\title{
Numerical Simulation of the lon Transport Behavior in Concrete under Coupled Axial Loading and Sulfate Attack
}

\author{
Wenzheng HE, Linsheng XU*, Lili WANG*
}

\begin{abstract}
During a sulfate attack on concrete, ions, which are transported to the interior of concrete through pores, react with the concrete components. The transport characteristics are affected by various factors. A chemical-mechanical coupling method for accurately evaluating the transport behavior of sulfate ions in concrete under stress conditions was proposed in this study to investigate the transport characteristics of these ions. The diffusion-reaction equations of sulfate ions were obtained based on the diffusion-reaction approach in combination with the mechanism of volume expansion under a sulfate attack and the influence of load on the concrete voidage. The constitutive response and crack density of the matrix were calculated according to the volumetric strain caused by external load and ettringite growth. Then, the diffusion coefficient of the equation was dynamically corrected. T'his phenomenon was a strongly coupled moving boundary problem, and the equations were solved using numerical method. A case study was conducted to analyze the distribution law of ionic concentration and volumetric strain obtained using the proposed method. Results demonstrate that the crack damage due to volumetric strain plays a major role in the diffusion of sulfate ions. The load has minimal effect on the transport behavior under a low stress level, and the water-cement ratio is negatively correlated with ion transport capacity. The proposed method serves as a reference for evaluating the durability of an underground structure in a sulfate formation.
\end{abstract}

Keywords: concrete; coupling; diffusion; modeling; sulfate attack

\section{INTRODUCTION}

Sulfate formation is widely distributed in China [1]. Given the various forms of pores in concrete, sulfate ions can easily enter the interior of concrete and react with its components to form ettringite; this phenomenon causes expansion and cracking in concrete and decreases the strength and bearing capacity of a concrete structure [2]. Sulfate attack, which is regarded as complicated and hazardous erosion, is one of the important factors influencing the durability of underground concrete structures. This process is an important part in the study of the durability of concrete [3].

Sulfate attack on concrete is a complex physicalchemical-mechanical process under the coupling of ion diffusion, chemical reaction, and mechanical damage. Various factors are involved in the sulfate attack on concrete. The high coupling degree between these factors poses a great challenge to the study of the durability of concrete during a sulfate attack.

Numerous studies on sulfate attack on concrete have been reported [4-8]. However, how to quantify the influence of microstructural evolution on the diffusion properties of microscopic ions should be further studied. Hence, a quantitative investigation of the factors influencing ion transport and accurate simulation of the entire process of sulfate attack on concrete are interesting and meaningful research endeavors.

On the basis of the above-mentioned analysis, this study established partial differential equations for the diffusion-reaction problem of sulfate ions under external loads by using chemomechanical mathematical method. The sulfate ion concentration and expansion strain distribution in concrete were analyzed. The influence of various factors on the transport behavior of ions was explored to accurately simulate the micro-macro damage process of concrete under sulfate attack. The results provide a reference for evaluating the durability of underground concrete structures in sulfate formation.

\section{STATE OF THE ART}

Scholars have carried out many studies on sulfate attack. These studies mainly focus on the experimental study of the sulfate ion transmission law, degradation of macroscopic mechanical properties, and theoretical model of sulfate attack based on mechanical and mathematical methods. Guo et al. [9] tested the sulfate ion concentration in the cement gangue filling material by chemical analytical method and analyzed the degradation law via scanning electron microscopy (SEM) and X-ray diffraction (XRD). However, the transport law of sulfate ions under the influence of various environmental factors was not studied in detail. Niu et al. [10] conducted a test of sulfate attack on shotcrete in a dry-wet alternate environment. They observed the phase composition and microstructure of shotcrete under sulfate attack via XRD, integrated thermal analysis, and SEM. The result showed that steel fiber concrete has better corrosion resistance than ordinary concrete. $\mathrm{Lu}$ et al. [11] investigated the damage characteristics of concrete under the action of sulfate attack and dry-wet alternation. The result showed that decreasing the water-cement ratio and adding a water-reducing agent can enhance the erosion resistance of high-strength concrete. However, they failed to analyze the diffusion behavior of sulfate ions. Stawiski et al. [12] immersed concrete specimens in sulfate solution in the laboratory for 5 years and tested their internal strength by using ultrasonic method. The test results showed heterogeneity of strength across the entire thickness of the tested elements. A drop in the mechanical properties of concrete was observed only in the close zone near the exposed surface. Although an experimental study can intuitively reflect the corrosion law of sulfate, sulfate attack on concrete is a complex coupling process of ion diffusion, chemical reaction, and mechanical damage. The evolution of material properties is influenced by many factors. Consequently, accurate analysis of the erosion process of concrete just by conducting indoor accelerated tests is difficult. At present, theoretical study of sulfate attack by using mathematical methods has become 
increasingly popular. These methods provide another powerful tool for studying sulfate attack in concrete in addition to experiments. Ikumi et al. [13-15] proposed a simplified chemical-mechanical model to evaluate the damage evolution of concrete structures exposed to sulfate environment. The model considered not only penetration acceleration caused by sulfate consumption and cracks but also the reduction of diffusion coefficient that resulted from pore filling to analyze the failure mode of concrete. Zuo et al. [16-17] established the diffusion model of sulfate ions in cement slurry according to Fick's second law and chemical reaction kinetics. They quantitatively analyzed the formation of gypsum and ettringite in the sulfate attack on cement paste. However, the model took diffusion coefficient as a constant and neglected the time-dependent property of a diffusion coefficient. Multon et al. [18] proposed a porous medium mechanical model to describe the expansion behavior of concrete materials under sulfate attack and evaluated the opening degree of local cracks under erosion combined with damage mechanics. Islam et al. [19] established a diffusion coefficient expression of sulfate related to humidity and temperature and proposed a comprehensive model considering the coupling effect of temperature and humidity on sulfate attack. The model was solved by finite element method to assess and predict the expansion failure of unsaturated cement-stabilized pavement. However, the coupling relationship between material damage accumulation and ionic diffusion was not considered in the model. Gouder et al. [20-21] established a diffusion reaction model of sulfate in concrete on the basis of the mixture theory framework. The model selected Helmholtz free energy and interaction momentum to simulate the diffusion of sulfate in concrete. However, the model cannot be used to predict the concentration of sulfate ion under the coupling of various environmental factors. Yin et al. [22-23] established a diffusion-reaction model to simulate the time-varying mechanical behavior of concrete under the coupling of axial load and sulfate attack on the basis of Fick's law and chemical reaction kinetics. The distribution of concentration of sulfate ion, gypsum, and ettringite was obtained. Li et al. [24-25] established the nonstationary diffusion reaction equation of sulfate ion on the basis of Fick's second law and calculated the damage and bearing capacity of the pile section through the damage evolution function. They also determined the relationship between the damage degree of the pile foundation and the bearing capacity of the pile. The above-mentioned studies regarded diffusion coefficient as a static value and failed to consider the time-dependent property. The proposed models cannot reveal the coupling relationship among different processes in sulfate attack. The existing theoretical models do not consider the time-varying process of surface sulfate ion concentration, thereby deviating from the actual state. These models cannot yet objectively reflect the actual erosion process.

These studies have mainly focused on the sulfate attack test or static erosion process on the basis of the diffusion-reaction equation. Few studies consider the entire process of ion transport, chemical reaction, and damage evolution, especially sulfate attack under the influence of multiple environmental factors. A novel method considering the time-varying effect of surface sulfate ion concentration was developed to explore the transport behavior of ions in concrete under coupled axial loading and sulfate attack in this study. The effects of water-cement ratio and stresses on the transport behavior of corrosive ions were discussed. This study is expected to serve as a reference for evaluating the durability of underground structures in sulfate formation.

The remainder of this study is organized as follows. Section 3 establishes a chemical-mechanical coupling method for modeling of sulfate attack on concrete under load. Section 4 discusses the distribution of ion concentration, internal strain, and the influence of stress and water-cement ratio on the transport behavior of sulfate ions. Finally, Section 5 summarizes the conclusions.

\section{METHODOLOGY}

\subsection{Mechanism of Sulfate Attack}

Based on the mechanism of sulfate attack on concrete [26], calcium hydroxide, C-S-H gel, and hydrated calcium aluminates are generated in the hydration reaction of cement. When the concrete is subjected to sulfate attack, sulfate ions are transported to the concrete through the concrete pore system and react with calcium hydroxide to generate secondary gypsum. Secondary gypsum reacts with calcium aluminate (hydrated calcium aluminates and tricalcium aluminate) to form ettringite (expansive corrosion product), thereby leading to expansion and cracking of concrete. The main chemical reactions are as follows:

Secondary gypsum:

$\mathrm{CH}+\mathrm{SO}_{4}^{2-} \rightarrow \mathrm{C}_{\bar{S}} \mathrm{H}_{2}+2 \mathrm{OH}^{-}$

where $\mathrm{CH}$ indicates calcium hydroxide. The secondary gypsum will further react with the calcium aluminate in concrete and generate ettringite:

Ettringite:

$$
\begin{aligned}
& C_{4} A \bar{S} H_{12}+2 C \bar{S} H_{2}+16 H \rightarrow C_{6} A \bar{S}_{3} H_{32} \\
& C_{3} A H_{6}+3 C \bar{S} H_{2}+20 H \rightarrow C_{6} A \bar{S}_{3} H_{32} \\
& C_{4} A H_{13}+3 C \bar{S} H_{2}+14 H \rightarrow C_{6} A \bar{S}_{3} H_{32}+C H \\
& C_{3} A+3 C \bar{S} H_{2}+26 H \rightarrow C_{6} A \bar{S}_{3} H_{32}
\end{aligned}
$$

where $C_{3} A$ indicates tricalcium aluminate and $H$ indicates $H_{2} O . C_{4} A \bar{S} H_{12}, C_{3} A H_{6}$, and $C_{4} A H_{13}$ are hydrated calcium aluminates generated in the hydration reaction. Eq. (2) to Eq. (5) may be briefly replaced by the following equation for convenience of calculation:

$C A+q C \bar{S} H_{2} \rightarrow C_{6} A \bar{S}_{3} H_{32}$

where $C A$ signifies an equivalent grouping of the reacting calcium aluminates $\left(C_{4} A \bar{S} H_{12}, C_{3} A H_{6}, C_{4} A H_{13}\right.$, and $\left.C_{3} A\right)$; and $q$ is the equivalent reacting coefficient of gypsum dissipation to produce ettringite [26].

\subsection{Diffusion-Reaction Equations}

Sulfate attack on concrete is a complex process, which can be summarized as follows. Sulfate ions are transported to the interior of concrete through the pores and react with 
the components in concrete, thereby leading to expansion and cracking of concrete. The transport rate of sulfate ions in concrete is influenced by microcracks. The load will cause tensile or compressive strain, which will not only aggravate or inhibit the generation and expansion of microcracks in concrete but also change the porosity of concrete. Accordingly, the diffusion coefficient of sulfate ions in concrete is significantly changed. A high degree of coupling exists between the factors involved in this process (Fig. 1). A chemomechanical mathematical method is employed to establish diffusion-reaction partial differential equations reflecting the coupling process.

When the concrete is subjected to sulfate attack, the 1D diffusion-reaction equation can be expressed as follows:

$$
\left\{\begin{array}{l}
\frac{\partial U_{\mathrm{SO}_{4}^{2-}}}{\partial t}=\frac{\partial}{\partial x}\left[D(x, t) \frac{\partial U_{\mathrm{SO}_{4}^{2-}}}{\partial x}\right]-\frac{\partial U_{D}}{\partial t} \\
U_{\mathrm{SO}_{4}^{2-}}(x, 0)=U_{0}, U_{\mathrm{SO}_{4}^{2-}}(0, t)=U_{s}(t), x \in(0, l)
\end{array}\right.
$$

where $U_{S_{4}^{2-}}$ is the concentration of sulfate ions in concrete, $U_{D}$ is the concentration of sulfate ions consumed in the chemical reaction, $D(x, t)$ is the diffusion coefficient, $U_{0}$ is the initial concentration of sulfate ions (initial condition), $l$ is the section width, $x$ is the section location, $t$ is the corrosion time, and $U_{s}(t)$ is the surface sulfate ion concentration (boundary condition).

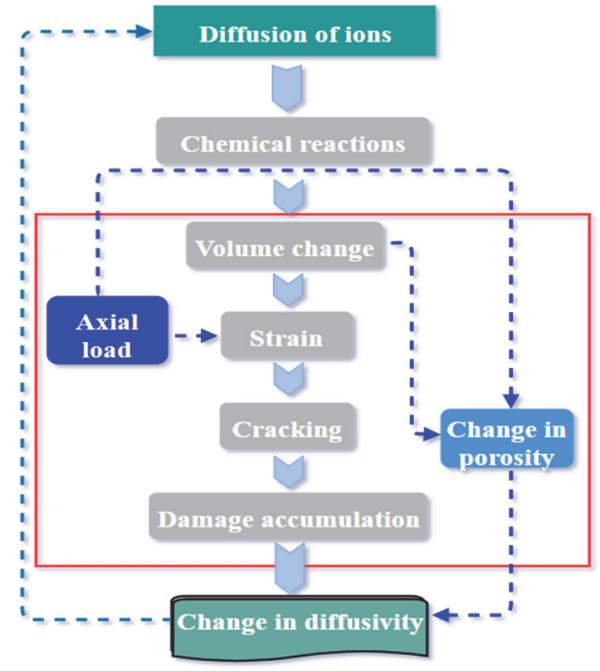

Figure 1 Coupling effects of sulfate attack on concrete

In the existing study of sulfate ion diffusion, the surface sulfate ion concentration of concrete has always been assumed as a constant value. However, experimental results show that the concentration of sulfate ions on a concrete surface is not a constant value in actual sulfate solution, but a variable over time, increases with the extension of soak time, and finally becomes stable. The study of the time-varying model of surface sulfate ion concentration on concrete is scarce. Nevertheless, the main conclusions can be drawn from the chloride diffusion test. Zhao et al. [27] proposed an exponential model of timevarying law of surface chloride ion concentration. The model has clear physical meaning and is consistent with practical experience, which can be applied to the study of the diffusion law of sulfate ions. The exponential model of surface sulfate ion concentration is proposed as follows:

$U_{s}(t)=U_{0}+U_{\max }\left(1-\mathrm{e}^{-a t}\right)$

where $U_{0}$ is the initial concentration of sulfate ions in concrete; $U_{\max }$ is the surface ion concentration after stabilization; $a$ is the dimensionless fitting parameter; $U_{\max }$ and $a$ can be influenced by environmental factors, such as solution concentration, temperature, and dry and wet conditions; and $U_{\max }$ is the linear function of the watercement ratio:

$U_{\max }=b_{1}(w / c)+b_{2}$

where $b_{1}$ and $b_{2}$ are fitting parameters.

Eq. (9) is substituted into Eq. (8) to obtain the following equation:

$U_{s}(t)=U_{0}+\left[b_{1}(w / c)+b_{2}\right]\left(1-\mathrm{e}^{-a t}\right)$

The existing experimental data are fitted by Eq. (10) [28], thereby showing that the model can be used to simulate the time-varying law of surface sulfate ion concentration.

During the diffusion process, sulfate ions react with calcium hydroxide to form secondary gypsum. The concentration of sulfate ions consumed in the reaction is related to that of calcium ions in the pore solution. The consumption of sulfate ions can be expressed as follows:

$$
\left\{\begin{array}{l}
\frac{\partial U_{D}}{\partial t}=k_{1} U_{S O_{4}^{2-}} U_{c a^{2+}} \\
U_{D}(x, 0)=0
\end{array}\right.
$$

where $k_{1}$ is the chemical reaction rate constant of Eq. (1), and $U_{\mathrm{Ca}^{2+}}$ is the concentration of calcium ions in the pore solution. The concentrations of calcium ions (i.e., 25 and $10 \mathrm{~mol} / \mathrm{m}^{3}$ at 273 and $373 \mathrm{~K}$, respectively) are approximately a linear function of temperature [16].

The secondary gypsum reacts with $C A$ in concrete, and ettringite is formed. The reaction rate equation is as follows:

$\left\{\begin{array}{l}\frac{\partial U_{C A}}{\partial t}=-\frac{k_{2} U_{D S O_{4}^{2-}} U_{C A}}{q} \\ U_{C A}(x, 0)=U_{C A 0}\end{array}\right.$

where $U_{C A}$ is the concentration of $C A$ in concrete, $U_{C A 0}$ is the initial concentration of $C A$ in concrete, and $k_{2}$ is the reaction rate constant of Eq. (6).

Ettringite is formed in the reaction of $C A$ and secondary gypsum, and the consumption of $C A$ is:

$U_{R C A}=U_{C A 0}-U_{C A}$

In combination with Eq. (7), Eq. (11), and Eq. (12), the diffusion-reaction equations for the sulfate erosion problem can be obtained. These equations are strongly coupled nonlinear partial differential equations. 


\subsection{Time-Varying Model of Diffusion Coefficient}

The diffusion coefficient $D(x, t)$ in the equation set proposed in Section 3.2 is not a constant, but a binary function about time and location. The mechanism of the time-varying property of diffusion coefficient can be summarized as follows. The growth of ettringite leads to volume expansion of concrete with the extension of attack time. If the tensile stress caused by volume expansion exceeds the tensile strength of concrete, then microcracks and macrocracks will be formed, thereby changing the transport characteristics (diffusion coefficient) of sulfate ions in concrete. The overall diffusion behavior of sulfate ions in concrete is determined by cracks. The number of microcracks in the attacked layer continuously increases, the leading edge of cracks moves forward, and the diffusion capacity will evolve from the surface to the interior with the extension of attack time.

The load can significantly influence the diffusion properties of ions. At low load levels (the strain caused by load does not exceed the critical strain of the concrete), the influence of external load on the diffusion behavior of sulfate ions can be equivalent to that of the change of porosity caused by the load. Under high load levels (the strain exceeds the critical strain), high strain will cause a large number of macro and microcracks inside the concrete, thereby significantly influencing the diffusion coefficient.

\subsubsection{Influence of Load on the Diffusion Coefficient}

The load can change the porosity of concrete, thereby leading to the change of diffusion coefficient (Fig. 2). The porosity under load is [29]:

$\Phi=\frac{\Phi_{0}}{1-\varepsilon_{v e}}\left[1-\frac{\left(4 G_{m}+3 K_{m}\right) \Theta}{4 G_{m}+3 K_{m} \Phi_{0}}\right]^{3}$

where $\Phi_{0}$ is the initial porosity; $\varepsilon_{v e}$ is the volumetric strain caused by external loads; $K_{m}$ is the bulk modulus of concrete, $K_{m}=\frac{E}{3 \cdot(1-2 \mu)} ; \mu$ is Poisson's ratio of concrete; and $G_{m}$ is the shear modulus of concrete, $\Theta=\sqrt[3]{1-\varepsilon_{v e}}$.

The linear strain is transformed into volumetric strain according to elastic mechanics:

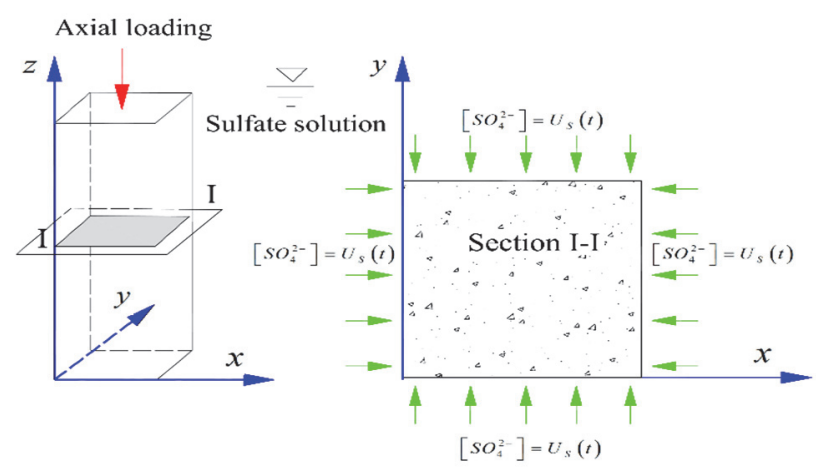

Figure 2 Model of sulfate attack under axial load [22]

$\varepsilon_{v e}=(1-2 \mu) \varepsilon_{l e}$ where $\varepsilon_{l e}$ is the linear strain caused by load, which can be calculated according to the axial load.

Initial porosity $\Phi_{0}$ can be calculated according to the Hansen model:

$\Phi_{0}=\frac{f_{v c}[(w / c)-0.36 \alpha]}{(w / c)+0.32}$

where $f_{v c}$ is the volume fraction of cement in concrete; $w / c$ is the water-cement ratio of concrete; and $\alpha$ is the hydration degree, $\alpha=1-\exp [-3.15(w / c)]$. The porosity of concrete under stress can be obtained by substituting Eq. (15) and Eq. (16) into Eq. (14).

When $0<\Phi<0.60$, the diffusion coefficient of sulfate ions in concrete, which has not been attacked, can be calculated according to the following formula [26]:

$$
\begin{aligned}
D_{0}= & D^{\mu}\left[0.001+0.07 \Phi^{2}+H(\Phi-0.18)\right. \\
& \left.\cdot 1.8 \cdot(\Phi-0.18)^{2}\right]
\end{aligned}
$$

where $D^{\mu}$ is the diffusion coefficient of attack ions in the free solution, and the diffusion coefficient of sulfate ions in water is $1.07 \times 10^{-9} \mathrm{~m}^{2} / \mathrm{s} . H$ is the Heaviside function, namely: $H(x)= \begin{cases}1 & x>0 \\ 0 & x \leq 0\end{cases}$

\subsubsection{Expansion Strain}

The ettringite first fills the pores of the concrete [30]. After reaching the maximum filling amount, the ettringite that continuously develops will squeeze the concrete capillary wall and produce circumferential dilatant stress around the pores, thereby leading to radial microcracks around the pores (Fig. 3). Consequently, the diffusion process of sulfate ions in concrete will be accelerated. The expansion strain is calculated according to the consumption of sulfate ions.

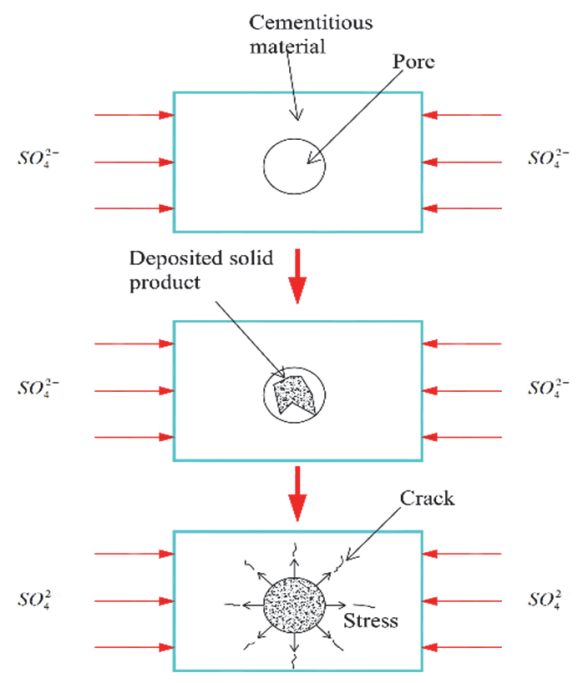

Figure 3 Strain and microcrack evolution mechanism

The reactions of the compounds in the aluminum phase can change the volume of concrete. The volume change of concrete per unit volume can be expressed as follows: 
$\Delta_{i}=\left(\frac{\Delta V}{V}\right)_{i} m_{V i} \frac{C_{i}}{\sum C_{i}}$

where $\left(\frac{\Delta V}{V}\right)_{i}$ is the volume change rate of ettringite formed by calcium aluminates in cement; $m_{V i}$ is the molar volume, where $i=1,2,3,4$, which corresponds to $C_{4} A \bar{S} H_{12}, C_{3} A H_{6}, C_{4} A H_{13}$, and $C_{3} A$; and $\frac{C_{i}}{\sum C_{i}}$ is the ratio of the initial content of the aluminum phase to the total amount.

The volume change rates (Tab. 1) of $C_{6} A \bar{S}_{3} H_{32}$ formed by $C_{4} A \bar{S} H_{12}, C_{3} A H_{6}, C_{4} A H_{13}$, and $C_{3} A$ can be calculated according to the density and molar volume of each reactant in Eq. (2) to Eq. (5) [30].

Table 1 Volume change in reactions involved in sulfate attack

\begin{tabular}{|l|c|c|}
\hline$i$ & Reaction & Volume change $/ \Delta V / V$ \\
\hline 1 & Eq. (2) & 0,55 \\
\hline 2 & Eq. (3) & 0,92 \\
\hline 3 & Eq. (4) & 0,48 \\
\hline 4 & Eq. (5) & 1,31 \\
\hline
\end{tabular}

Considering the ettringite consumed by filling concrete pores, the average volumetric expansion strain caused by ettringite growth is as follows:

$\varepsilon_{v s}=\max \left(U_{R C A} \sum_{i=1}^{4} \Delta_{i}-f \Phi, 0\right)$

where $f$ is the volume fraction of the initial porosity being filled with ettringite, which is $0.3-0.4 ; \Phi$ is the porosity, which is calculated according to Eq. (14); and $U_{R C A}$ is the molar concentration of $C A$ involved in sulfate attack on concrete, which is calculated through Eq. (13).

Considering the volume change under axial load, the equivalent strain of concrete can be obtained according to elasticity theory:

$$
\varepsilon_{v}=\varepsilon_{v s}+\varepsilon_{v e}
$$

The following expression can be derived by substituting Eq. (15) into Eq. (20):

$\varepsilon=\frac{1}{3}\left[\varepsilon_{v s}+(1-2 \mu) \varepsilon_{l e}\right]$

where $\varepsilon$ is the equivalent linear strain under the coupling of axial force and corrosion expansion.

\subsubsection{Influence of Crack on the Diffusion Coefficient}

Crack density function is introduced to quantitatively characterize the evolution characteristics of concrete microcracks [26]:

$d_{c r}= \begin{cases}0 & \varepsilon \leq \varepsilon_{t h} \\ \chi\left(1-\frac{\varepsilon_{t h}}{\varepsilon}\right) \kappa & \varepsilon>\varepsilon_{t h}\end{cases}$ where $d_{c r}$ is the crack density, and $\chi$ and $\kappa$ are the material parameters related to the strength grade of concrete.

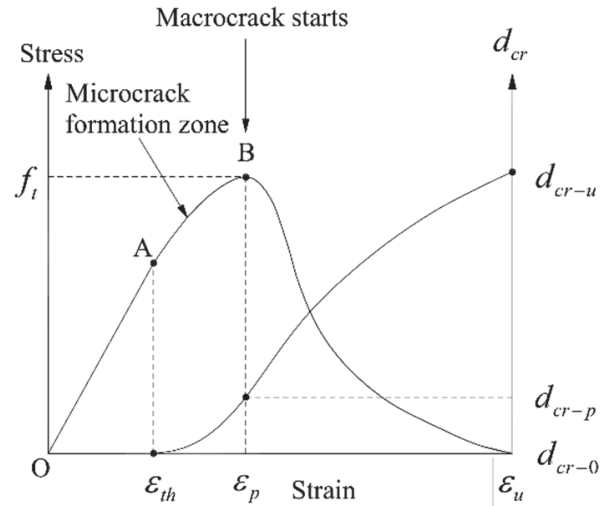

Figure 4 Tensile stress-strain constitutive model and damage evolution curve of concrete

The tensile constitutive model and damage evolution curve of concrete are shown in Fig. 4. $\sigma$ is the expansion stress of concrete; $f_{t}$ is the tensile strength; $d_{c r-0}$ is the crack density corresponding to $\varepsilon_{t h}$ (critical strain: microcracks are formed); $d_{c r-0}=0 ; d_{c r-p}$ is the crack density corresponding to $\varepsilon_{p}$ (peak strain); $d_{c r-p}=0,182$; $d_{c r-u}$ is the crack density corresponding to $\varepsilon_{u}$ (ultimate tensile strain); and $d_{c r-u}=0,712$ [26].

The diffusion coefficient can be expressed as follows:

$$
D= \begin{cases}D_{0}\left(1+\frac{32}{9} d_{c r}\right) & d_{c r-0}<d_{c r} \leq d_{c r-p} \\ D_{0}\left[\left(1+\frac{32}{9} d_{c r}\right)+\frac{\left(d_{c r}-d_{c r-p}\right)^{2}}{d_{c r-u}-d_{c r}}\right] & d_{c r-p}<d_{c r} \leq d_{c r-u} \\ D^{\mu} & d_{c r-u}<d_{c r}\end{cases}
$$

The diffusion coefficient of sulfate ions under loadcorrosion coupling can be obtained according to Eq. (21) to Eq. (23). Variable $d_{c r}$ is a function of time $t$ and location $x$. Hence, diffusion coefficient $D$ is also a function of $t$ and $x$, which is written as $D(x, t)$.

\section{$4 \quad$ RESULT ANALYSIS AND DISCUSSION}

The transport behavior of sulfate ions in concrete under load is analyzed according to the method proposed in Section 3.2. The diffusion-reaction partial differential equations are obtained by combining Eq. (7), Eq. (11), and (12). The diffusion coefficient $D(x, t)$ is calculated by the method proposed in Section 3.3. This expression is a strongly coupled nonlinear equation set, and the Boundary condition is a function of independent variable $t$. We cannot obtain the analytical solution of the equation set. This study uses ComsolMultiphysics to solve the equation set through numerical analysis. 


\begin{tabular}{|c|c|c|c|c|}
\hline Parameters & Symbol & Unit & Value & Source \\
\hline Initial concentration of sulfate ion in concrete & $U_{0}$ & $\mathrm{~mol} / \mathrm{m}^{3}$ & 0 & Known \\
\hline Concentration of sulfate ion on the concrete surface after stabilization & $U_{\max }$ & $\mathrm{mol} / \mathrm{m}^{3}$ & 75 & Known \\
\hline Side length of the specimen & $L$ & $\mathrm{~m}$ & 0,1 & Known \\
\hline Dimensionless fitting parameter & $a$ & & 0,007 & [27] \\
\hline Dimensionless fitting parameter & $b_{1}$ & & 50,2 & [28] \\
\hline Dimensionless fitting parameter & $b_{2}$ & & 42,0 & {$[28]$} \\
\hline Concentration of calcium ions in solution & $U_{c a^{2+}}$ & $\mathrm{mol} / \mathrm{m}^{3}$ & 21,5 & [16] \\
\hline Initial concentration of $C A$ & $U_{\mathrm{CA} 0}$ & $\mathrm{~mol} / \mathrm{m}^{3}$ & 450 & Known \\
\hline Equivalent reacting coefficient & $q$ & & 2,46 & {$[26]$} \\
\hline Material parameter & $\chi$ & & 1,77 & {$[30]$} \\
\hline Material parameter & $\kappa$ & & 5,61 & {$[30]$} \\
\hline Chemical reaction rate constant of Eq. (11) & $k_{1}$ & $s^{-1}$ & $1,22 \times 10^{-8}$ & {$[16]$} \\
\hline Chemical reaction rate constant of Eq. (12) & $k_{2}$ & $s^{-1}$ & $1,22 \times 10^{-9}$ & [16] \\
\hline Water-cement ratio & $w / c$ & & 0,58 & Known \\
\hline
\end{tabular}

\subsection{Calculation Parameters}

The cubic concrete specimen with a side length of 0.1 $\mathrm{m}$ was subjected to $1 \mathrm{D}$ erosion numerical simulation. The specimen was immersed in sulfate solution, and one surface was eroded. The other surfaces were closed boundaries (Fig. 5). The parameters are listed in Tab. 2.

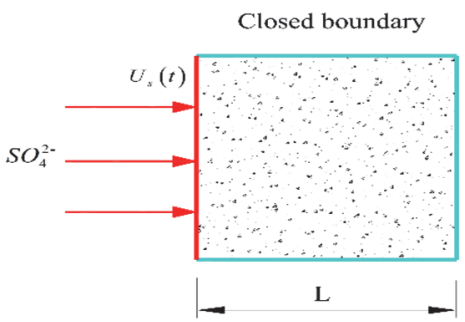

Figure $51 \mathrm{D}$ erosion

\subsection{Calculation Results}

After solving the partial differential system, the distribution law of sulfate ion concentration, $C A$ concentration, and expansion strains are obtained (Fig. 6 to Fig. 12). Fig. 6 describes the change of surface sulfate ion concentration with diffusion time. The surface sulfate ion concentration increases over time. In the first 180 days, the ion concentration on the concrete surface sharply increases, and the increase rate decreases in the later period. The concentration tends to be stable after 400 days.

Fig. 7 shows the distribution of sulfate ion concentration at different points inside the concrete. The sulfate ion concentration is positively correlated with the diffusion time and negatively correlated with erosion depth. The concentration is low when the surface ion is far from the surface. The erosion rate decreases over time. The erosion depth is $18 \mathrm{~mm}$ in the first 90 days. On the 600th day, the erosion depth is only $30 \mathrm{~mm}$.

This figure demonstrates that the sulfate ion concentration at a certain depth near the surface no longer decrease with the increase in depth and extension of corrosion time, but it is consistent with the surface ion concentration, thereby reaching a stable value. Microcracks form in the corrosion layer with the increase in erosion time, and the damage evolves from the outside to the inside. The leading edge of the corrosion layer moves forward, and the effect of boundary movement occurs. Concrete has been completely corroded and failed in this area.

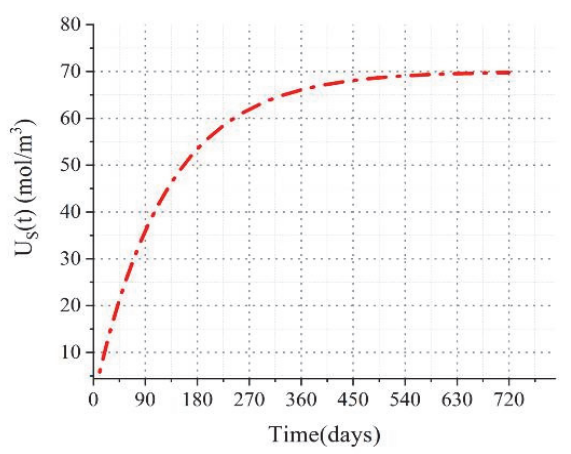

Figure 6 Changes of surface sulfate ion concentration over time

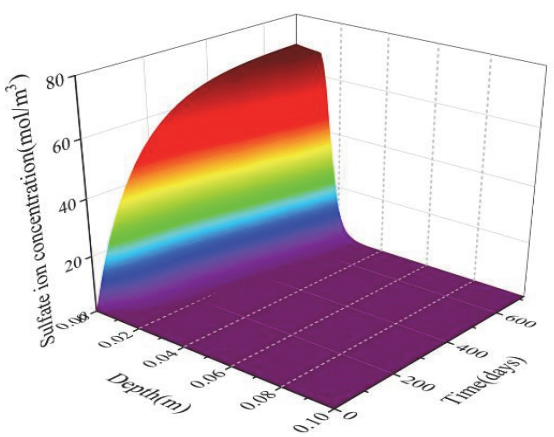

Figure 7 Changes of sulfate ion concentration with time and position

Fig. 8 presents the comparisons of the proposed model with the sulfate ion concentration from Zuo et al. It may be seen from Fig. 8 that the surface sulfate ion concentration calculated according to the Zuo's model is a constant value, which deviates from the actual situation. The model proposed in this study shows the time-varying effect of surface sulfate ion concentration, the transmission of sulfate ion can therefore be better evaluated.

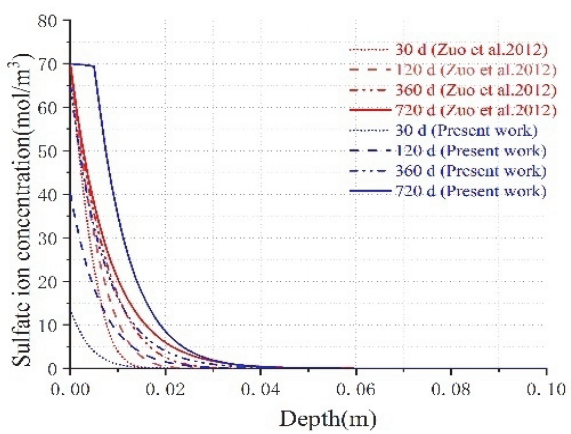

Figure 8 Comparisons of the proposed model with the sulfate ion concentration from Zuo et al. 
Fig. 9 shows the change of sulfate ion concentration in concrete with position and diffusion time. At the initial diffusion stage, sulfate ion had not yet participated in the chemical reaction, and the concentration of consumed sulfate ion was zero. However, the sulfate ions reacted with calcium hydroxide in concrete as they diffused, and secondary gypsum was produced. The chemical reaction rate was small due to the low concentration of sulfate ion in the initial stage. The chemical reaction rate gradually increased in the later period with the increase in the ion concentration. On the 720th day, the concentration of sulfate ion consumed on the specimen surface was 910 $\mathrm{mol} / \mathrm{m}^{3}$.

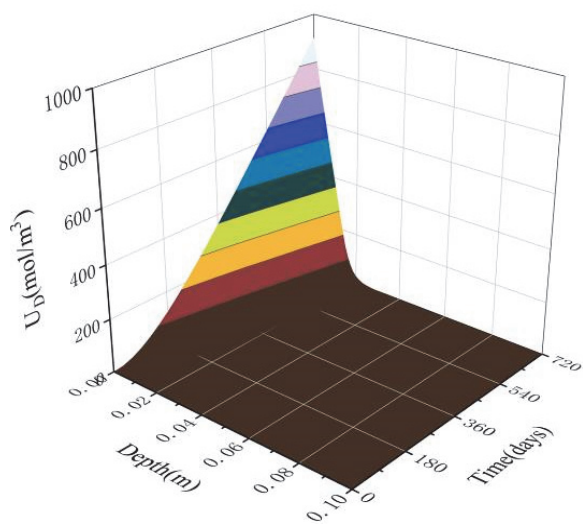

Figure 9 Variation of consumed sulfate ion concentration with time and position

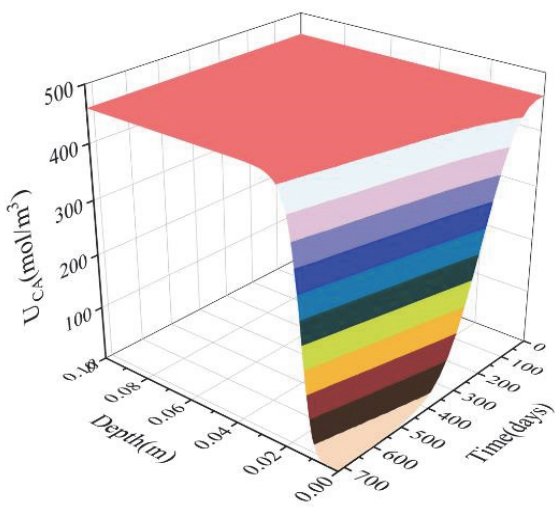

Figure 10 Changes of $\mathrm{CA}$ concentration with time and position

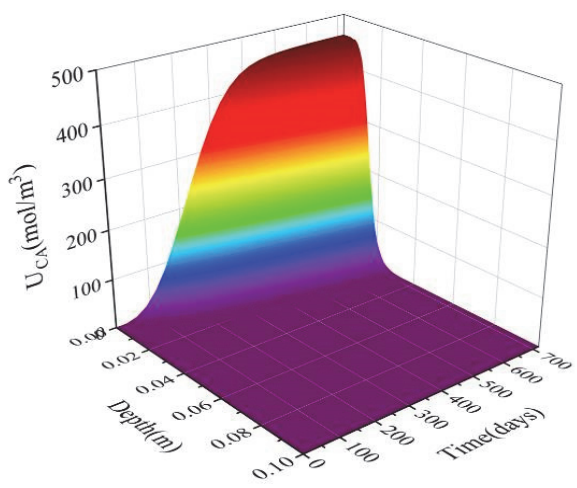

Figure 11 Change of consumed CA concentration with time and position

Fig. 10 shows the change of $C A$ concentration in concrete. Fig. 11 shows the change of consumed $C A$ concentration, which is calculated according to Eq. (13). The distribution law of consumed $C A$ is similar to that of the sulfate ion (Fig. 7). The $C A$ concentration is negatively correlated with corrosion depth. On the 480th day, the $C A$ concentration near the surface is zero, thereby indicating that $C A$ at this position has all been consumed in the reaction.

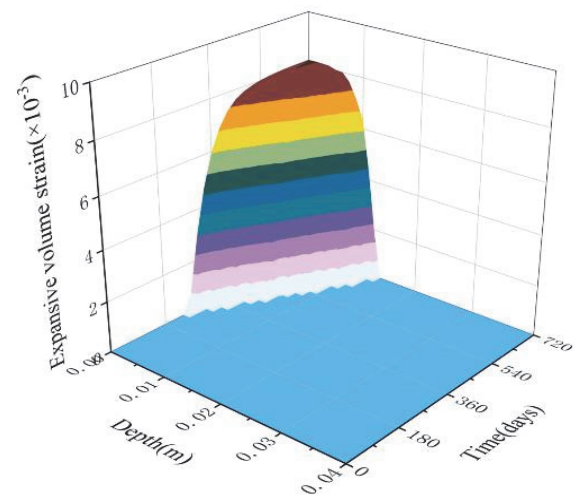

Figure 12 Distribution of expansion strain in the specimen

Fig. 12 presents the distribution of expansion volumetric strain of the concrete caused by ettringite growth. The change of expansion volumetric strain in the specimen is similar to that of consumed $C A$ concentration (Fig. 11). However, the ettringite crystal should be used to fill the pores from the beginning of diffusion until the 260th day. Therefore, the expansion volumetric strain at each position in concrete is equal to zero. After the 260th day, volume expansion occurs on the concrete surface, and the expansion volumetric strain increases with the extension of diffusion time. On the 720th day, the expansion volumetric strain on the concrete surface $(x=0.00 \mathrm{~m})$ is 0.008 , thereby far exceeding the limit expansion strain of the concrete material. At this time, the specimen has just begun to expand at $x=0.014 \mathrm{~m}$, and the concrete within $0.014 \mathrm{~m}$ from the surface has been completely destroyed.

\subsection{Parametric Analysis}

Different loads and water-cement ratios are considered in the model, and the influence of various parameters on the transport behavior of sulfate ions is analyzed. The calculation results are shown in Fig. 13 and Fig. 14.

Fig. 13 presents the transport laws of sulfate ions under different loads (270 and 630 days), where $\omega$ is the stress level, $\omega=\sigma / f_{u}$, and $f_{u}$ is the ultimate strength. The overall distribution law of sulfate ions under load is consistent with that under the unstress state. However, load has different effects on the ion concentration distribution at varying time points. On the 270th day (Fig. 13a), almost no difference is observed in the concentration of ions under different stress levels because the concrete has not yet cracked. The influence of external load on the diffusion behavior of ions is mainly reflected by the influence of porosity change on the diffusion coefficient. Porosity slightly changes under load. Therefore, load has minimal influence on the ion concentration distribution.

However, the concentration curves show an obvious difference on the 630th day (Fig. 13b). The ion content is low when the stress level is high. This phenomenon occurs because cracks have formed, and they play a major role in ion diffusion. The compressive stress suppresses the expansion strain, thereby closing several microcracks and minimizing the internal damage of concrete caused by expansion. By contrast, tensile stress intensifies the 
internal cracking of concrete. Nevertheless, load has a slight effect on ion transmission.

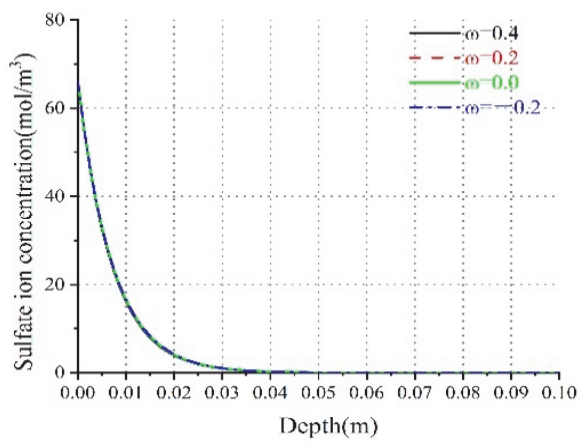

a) Sulfate ion concentration curve on the 270th day

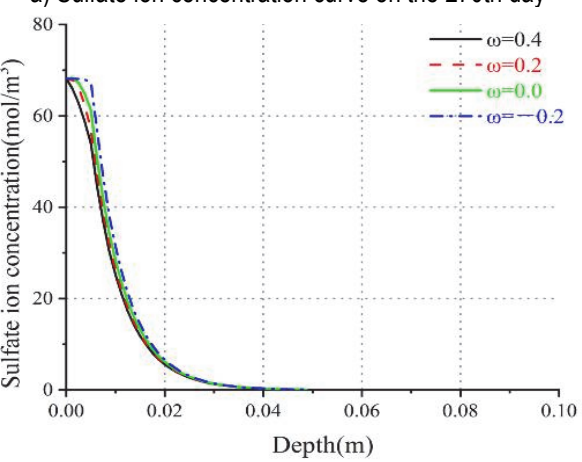

b) Sulfate ion concentration curve on the 630th day Figure. 13 Influence of load on the ion concentration

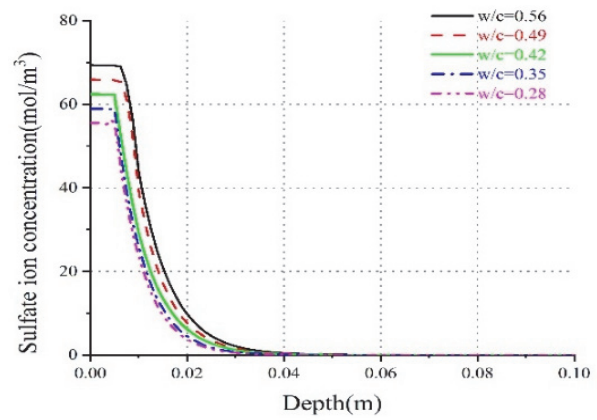

Figure. 14 Influence of water-cement ratio on the ion concentration

Fig. 14 shows the transport law of sulfate ions in concrete with different water-cement ratios (630 days). The porosity and surface sulfate ion concentration of concrete with diverse water-cement ratios show obvious difference in the time-varying law, thereby significantly influencing the transport characteristics of erosion ions in concrete. The distribution rules of ion concentration are similar under different water-cement ratios. Ion concentration is negatively correlated with water-cement ratio. When $w / c=0.56$ and 0.28 , the ion concentrations on the surface of the specimen are 70 and $56 \mathrm{~mol} / \mathrm{m}^{3}$, respectively, with a difference of $20 \%$. This finding indicates that water-cement ratio has a significant influence on the transport characteristics of ion.

\section{CONCLUSION}

A novel method based on the diffusion-reaction approach was developed to simulate the transport behavior of ions under coupled axial loading and sulfate attack. This work was carried out to explore the transport characteristics of sulfate ion in concrete under axial load. A case study was conducted to analyze the distribution law of ionic concentration and volumetric strain obtained using the proposed methods. The following conclusions could be drawn:

(1) Crack plays a major role in the diffusion of sulfate ion. The leading edge of the cracks continuously moves forward with the increase of corrosion time and the number of cracks in the eroded layer, thereby resulting in boundary movement. The diffusion capacity evolves from the outside to the inside of the concrete.

(2) The overall distribution of acid ions under load is similar to that in the unstress state. The concentration of ion diffusion is negatively related to stress. Nevertheless, load has a slight effect on ion transmission.

(3) Water-cement ratio can significantly influence the transport characteristics of ion, and the ion diffusion capacity is negatively correlated with water-cement ratio.

The time-varying effects of diffusion coefficients due to the coupling of axial load and corrosion expansion are considered in the proposed method to accurately evaluate the transport behavior of sulfate ions in concrete. However, these transport behaviors of sulfate ions in concrete are influenced by many factors. The proposed method is limited to considering the effect of axial load and watercement ratio. Other influencing factors should be considered in future studies.

\section{Acknowledgements}

This work was supported by youth project of science and technology research program of Chongqing Education Commission of China (Grant Nos. KJQN201904004), and the Open Fund Project of Chongqing Jiaotong University Municipal Key Laboratory of Mountain Highway \& Waterway Transportation Geological Disaster Reduction (Grant Nos. kfxm2018-08).

\section{REFERENCES}

[1] Yao, M. B. \& Li, J.P. (2019). Distribution behavior of sulfate erosion in concrete piles under water pressure. Journal of Tongji University (Natural Science), 47(08), 1131-1136.

[2] Cefis, N. \&Comi, C. (2016). Degradation of Concrete Structures due to External Sulfate Attack. Key Engineering Materials, 711, 310-318. https://doi.org/10.4028/www.scientific.net/KEM.711.310

[3] Pan, H. M., Wang, S. W., \& ZHAO, Q. X. (2018). Loading Damage Model of Early Disturbed Concrete under Sulfate Attack. China Railway Science,39(1), 23-30.

[4] Solonenko, I. (2019). The use of cement concrete pavements for roads, depending on climatic conditions. Tehnički glasnik, 13(3), 235-240. https://doi.org/10.31803/tg-20190518181647

[5] Chaunsali, P., Mondal, P., \& Bullard, J. (2015). Influence of calcium sulfoaluminate (CSA) cement content on expansion and hydration behavior of various ordinary portland cementCSA blends. Journal of the American Ceramic Society, 98(8), 2617-2624. https://doi.org/10.1111/jace.13645

[6] Soive, A., Tran, V. Q., \& Gasc-Barbier, M. (2019). The advantages of using a geochemical transport model including thermodynamic equilibrium, kinetic control and surface complexation to simulate the durability of concretes exposed to chlorides and sulphates. European Journal of Environmental and Civil Engineering, 23(5), 552-563. 
https://doi.org/10.1080/19648189.2018.1446363

[7] Soive, A. \& Tran, V. Q. (2017). External sulfate attack of cementitious materials: New insights gained through numerical modeling including dissolution/precipitation kinetics and surface complexation. Cement and Concrete Composites, 83, 263-272.

https://doi.org/10.1016/j.cemconcomp.2017.07.024

[8] Drapaluk, M. (2019). Influence of reinforced concrete forming features on mechanical characteristics. Tehnički glasnik, 13(2), 86-91. https://doi.org/10.31803/tg-20180310210604

[9] Guo, Y. X., Wang, P., Feng, G. R., Qi, T. Y., \& Li, Q. D. (2020). Experimental study on diffusion process of sulfate ion in cemented gangue backfill material. Advances in Civil Engineering, 2020(4), 1-14. https://doi.org/10.1155/2020/5846397

[10] Niu, D. T., Wang, J. B., \& Ma, R. (2016). Sulfate Attack Test of Shotcrete Under Dry-wet Alternation. China Journal of Highway and Transport, 29(2), 82-89.

[11] Lu, J. Z., Liu, Y., Zhu, K. F., \& Shao, Y. M. (2017). Damage behaviors of concrete due to sulfate attack in wet-dry cycle environment after experiencing historical load. Concrete, (2), 37-41.

[12] Stawiski, B. \& Kania, T. (2019). Examining the distribution of strength across the thickness of reinforced concrete elements subject to sulphate corrosion using the ultrasonic method. Materials, 12(16), 2519-2535. https://doi.org/10.3390/ma12162519

[13] Ikumi, T., Cavalaro, S. H., Segura, I., \& Aguado, A. (2014). Alternative methodology to consider damage and expansions in external sulfate attack modeling. Cement and concrete research, 63, 105-116. https://doi.org/10.1016/j.cemconres.2014.05.011

[14] Ikumi, T., Cavalaro, S. H., Segura, I., de la Fuente, A., \& Aguado, A. (2016). Simplified methodology to evaluate the external sulfate attack in concrete structures. Materials \& Design, 89, 1147-1160. https://doi.org/10.1016/j.matdes.2015.10.084

[15] Ikumi, T. \& Segura, I. (2019). Numerical assessment of external sulfate attack in concrete structures. A review. Cement and Concrete Research, 121, 91-105. https://doi.org/10.1016/j.cemconres.2019.04.010

[16] Zuo, X. B., Sun, W., \& Yu, C. (2012). Numerical investigation on expansive volume strain in concrete subjected to sulfate attack. Construction and Building Materials, 36, 404-410 https://doi.org/10.1016/j.conbuildmat.2012.05.020

[17] Zuo, X. B., Wang, J. L., Sun, W., Li, H., \& Yin, G. J. (2017). Numerical investigation on gypsum and ettringite formation in cement pastes subjected to sulfate attack. Computers and Concrete, 19(1), 19-31. https://doi.org/10.12989/cac.2017.19.1.019

[18] Multon, S. \& Sellier, A. (2019). Expansion modelling based on cracking induced by the formation of new phases in concrete. International Journal of Solids and Structures, 160, 293-306. https://doi.org/10.1016/j.ijsolstr.2018.11.001

[19] Islam, M. A., Golrokh, A. J., \& Lu, Y. (2019). ChemomechanicalModeling of Sulfate Attack-Induced Damage Process in Cement-Stabilized Pavements. Journal of Engineering Mechanics, 145(1), 1-11. https://doi.org/10.1061/(ASCE)EM.1943-7889.0001545

[20] Gouder, C. \& Saravanan, U. (2016). Modeling diffusion of sulfate through concrete using mixture theory. ActaMechanica, 227(11), 3123-3146. https://doi.org/10.1007/s00707-015-1539-4

[21] Gouder, C. \& Saravanan, U. (2018). Modeling diffusion and reaction of sulfates with cement concrete using mixture theory. ActaMechanica, 229(3), 1353-1385. https://doi.org/10.1007/s00707-017-2035-9

[22] Yin, G. J., Zuo, X. B., Tang, Y. J., Ayinde, O., \& Wang, J. L. (2017). Numerical simulation on time-dependent mechanical behavior of concrete under coupled axial loading and sulfate attack. Ocean Engineering, 142, 115-124. https://doi.org/10.1016/j.oceaneng.2017.07.016

[23] Yin, G. J., Zuo, X. B., Sun, X. H., \& Tang, Y. J. (2019). Macro-microscopically numerical analysis on expansion response of hardened cement paste under external sulfate attack. Construction and Building Materials, 207, 600-615. https://doi.org/10.1016/j.conbuildmat.2019.02.159

[24] Li, J. P., Xie, F., Li, L., Li, L., \& Zhao, G. W. (2019). Damage effect of concrete cast-in-situ piles under sulfate attack. Journal of Harbin Institute of Technology, 51(06), 95-100.

[25] Li, J. P., L, X. F., Li, L., \& Zhang, Y. (2016). Axial Bearing Behavior of Deteriorated Foundation Pile Under Sulfate Attack. Journal of Shanghai Jiaotong University, 050(011), 1761-1766.

[26] Gao, R. D. (2010). Micro-macro degadation regularity of sulfate attack on concrete under complex environments. $\mathrm{Ph}$ D Thesis, Tsinghua University.

[27] Zhao, Y. X., Wang, C. K., Jin, W. L., \& Xu, C. (2010). Experimental analysis on time-dependent law of surface chloride ion concentration of concrete. Journal of CivilArchitectural \& Environmental Engineering, 032(3), 813. https://doi.org/10.1002/9781119204831.ch6

[28] Liu, R. X. (2019). Study on Damage and Fracture Mechanism of Concrete under the Sulphate Erosion and High Strain Rate Load. Ph D Thesis, China University of Mining and Technology.

[29] Jin, L. \& Du, X. L. (2013). Variation of porosity and its effect on the deformation process of concrete. Engineering Mechanics, 30(6), 183-190.

[30] Sarkar, S., Mahadevan, S., Meeussen, J. C. L., Van der Sloot, H., \& Kosson, D. S. (2010). Numerical simulation of cementitious materials degradation under external sulfate attack. Cement and Concrete Composites, 32(3), 241-252. https://doi.org/10.1016/j.cemconcomp.2009.12.005

\section{Contact information}

Wenzheng HE, PhD, Lecturer

1) School of Civil Engineering, Chongqing Jiaotong University,

2) School of Urban Construction Engineering, Chongqing Radio \& Television

University,

No.15 Siyuan Road, Hechuan District, Chongqing, China

E-mail: hewenzheng1982@126.com

Linsheng XU, PhD, Professor

(Corresponding author)

School of Civil Engineering, Chongqing Jiaotong University,

No.66 Xuefu Road, Nanan District, Chongqing, China

E-mail: phoniex8210@sina.com

\section{Lili WANG, Master}

(Corresponding author)

School of Management, Cardiff Metropolitan University,

Llandaff Campus, Western Avenue, Cardiff,CF5 2YB, Wales

E-mail: liliwang1006@126.com 